\section{El Estado Palestino: necesidad y solución'}

Recibido: 05.09.2014 / Aprobado: 15.10.2014

Por Mohamed Saadat ${ }^{2}$

\section{RESUMEN}

Hablar del conflicto en el Medio Oriente significa hablar de más de 66 años de guerras y masacres. Un conflicto en el que una minoría extranjera inmigrante expulsa y desplaza al pueblo originario de su tierra y establece un Estado extranjero invasor. Significa hablar de refugiados, prisioneros, asentamientos, muros, justicia internacional, protección a la ley internacional y responsabilidad de la comunidad internacional ante los derechos del pueblo palestino.

Estos son temas que nos obligan a buscar una solución justa y definitiva a este conflicto, algo que la mayor parte de la comunidad internacional exige, sobre todo después de las últimas y criminales masacres cometidas por parte de Israel en la Franja de Gaza.

En este caso específico, hablar de soluciones no significa hablar de posibilidades sino de derechos, necesidades, obligaciones y valores humanos.

Palabras clave: Palestina, conflicto, guerra, derechos humanos, Gaza.

\section{ABSTRACT}

Discussing the Middle East conflict means discussing over 66 years of wars and massacres. It is a conflict in which an immigrant minority expels and displaces the indigenous people of their land and establishes an invading foreign state. It means speaking about refugees, prisoners, settlements, walls, international justice, international law protection, and responsibility of the international community for the Palestinian people's rights.

These are issues that commit us to seek a just and lasting solution to this conflict, something that most of the international community demands, especially after the latest and criminal massacres committed by Israel in the Gaza Strip.

In this specific case, discussing solutions does not mean to speak of possibilities but rather of rights, needs, obligations, and human values.

Keywords: Palestine, conflict, war, human rights, Gaza.

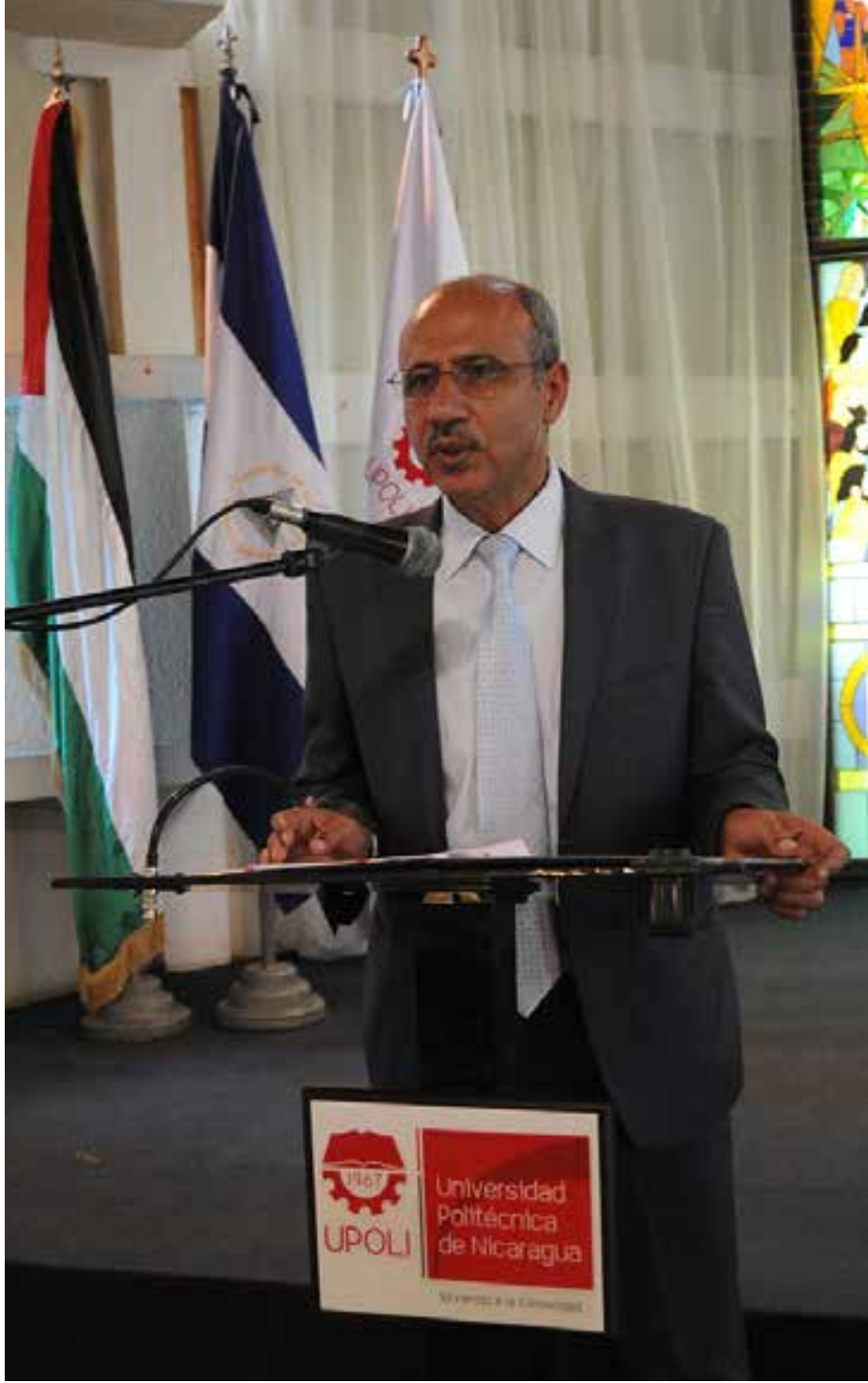

Excelentisimo Señor Embajador del Estado de Palestina en Nicaragua, Mohamed Saadat dictando la conferencia magistral.

Foto: Relaciones Públicas UPOLI

\section{RESEÑA HISTÓRICA}

Palestina es una región situada en la orilla oriental del Mar Mediterráneo en la Zona de Asia conocida como Medio Oriente, limita al Norte con el Líbano y Siria, al Este con Jordania y al Sur con Egipto.

- Los Cananeos la habitaban hace 3,000 años antes de Cristo.

- El área de Palestina histórica es de 27,009 $\mathrm{km}^{2}$.

- El área de Cisjordania es de 5,844 km², casi el 21.6\% de Palestina Histórica.

- La Franja de Gaza mide $365 \mathrm{~km}^{2}, 1.3 \%$ de Palestina Histórica.

1 Conferencia Magistral dictada en el marco de la Cátedra Interuniversitaria Cultura de Paz "José Miguel Torres h.", en la Universidad Politécnica de Nicaragua (UPOLI), el 04 de septiembre de 2014.

2 Excelentísimo Señor Embajador del Estado de Palestina en Nicaragua. 
Según las estadísticas de finales del año 2012, el total de la población palestina era aproximadamente de 11.2 millones de habitantes, el número de palestinos en Gaza y Cisjordania, se estima en 4.2 millones. (Cisjordania 2.6 millones y Gaza 1.6 millones)

En los territorios ocupados en 1948 viven casi 1.4 millones de palestinos.

El resto vive fuera de Palestina.

Por su ubicación estratégica como enlace entre Asia y África y su cercanía a los espacios marítimos en una zona llena de petróleo, Palestina siempre ha sido objetivo de invasiones extranjeras, como por ejemplo los Romanos, los Griegos, Cruzadas Europeas Etc.

En 1516 hasta 1917, Palestina era colonia del Imperio Otomano.

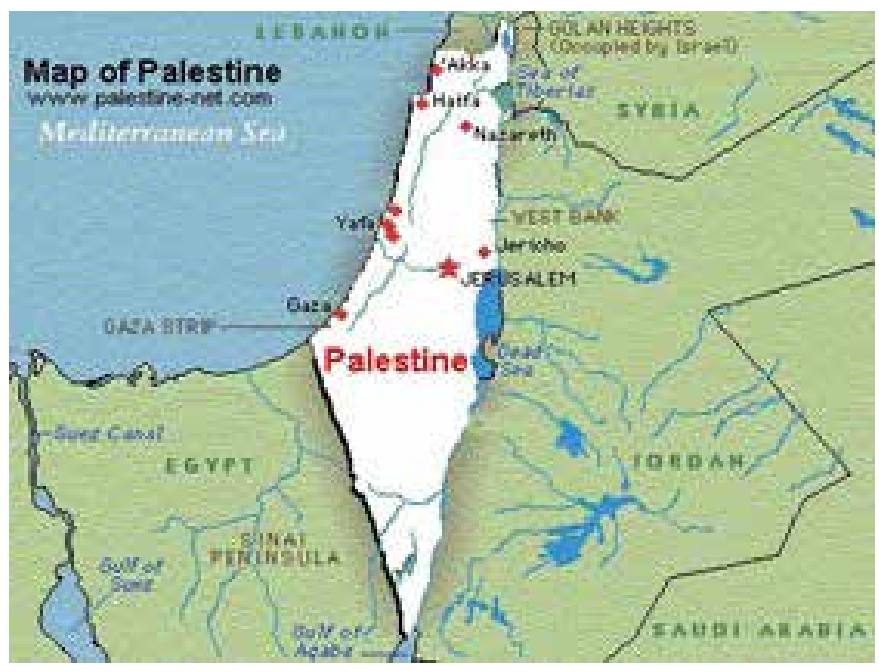

\section{ORIGEN DEL CONFLICTO}

El origen de este conflicto, comienza en 1897, cuando aparece el Movimiento Sionista públicamente como un Movimiento nacionalista, colonialista y racial que llamó a la creación de un Estado para los judíos en el primer congreso del Movimiento Sionista en Basilea (Suiza) bajo el liderazgo de Theodor Herzl.

En este congreso participaron 204 miembros judíos de 15 países. Las decisiones que se tomaron en el congreso consisten en lo siguiente:
1. El objetivo del Movimiento Sionista es el crear un hogar nacional para el pueblo judío en Palestina a través de los siguientes métodos:

- Fomentar la migración judía hacia Palestina.

- Organizar a los judíos y ligarlos al Movimiento Sionista.

- Tomar las medidas necesarias para garantizar el apoyo internacional al objetivo sionista (darle legitimidad mundial).

2. Formar el Movimiento Sionista Internacional bajo el liderazgo de Theodor Herzl.

3. Formar un aparato ejecutivo (la Agencia Judía) para ejecutar las decisiones tomadas por el congreso y recaudar fondos con el objetivo de crear un fondo nacional para comprar tierras y mandar a los migrantes judíos a construir colonias judías en Palestina.

A partir de aquel momento el movimiento sionista empezó hacer contactos con las fuerzas internacionales para lograr este objetivo y entre estas fuerzas, Inglaterra apoyó este planteamiento.

Se plantea por parte del Movimiento Sionista que el conflicto tiene un carácter religioso, lo cual no es verdad porque en Palestina siempre hubo convivencia entre musulmanes, judíos y cristianos.

Este conflicto es puramente político pero el Movimiento Sionista trata de darle un carácter religioso a través de conceptos como (El Pueblo de Dios y la Tierra Prometida) utilizando a los judíos para lograr objetivos ocultos, raciales y expansionistas.

Actualmente podemos ver muchos inmigrantes cristianos que emigraron hacia Israel y no tienen nada que ver con la religión judía, lo que demuestra que el objetivo es acumular inmigrantes para utilizarlos en las guerras contra el pueblo palestino y los pueblos árabes.

Cabe mencionar que en 1896, Herzl en su libro el Estado Judío, propone Argentina como otra alternativa para la creación del Estado Judío y también se propuso el Este de África como opción lo que fue aprobado por el Movimiento Sionista en aquel momento además de otras opciones. 
En este caso preguntamos ¿Qué hubiera pasado si Inglaterra hubiera regalado el Este de África en vez de Palestina al Movimiento Sionista?

¿Acaso se convertiría el Este de África en tierra prometida? Esto demuestra que lo que le interesaba al Movimiento Sionista es un lugar para ejercer sus ideas expansionistas para construir su "Gran Israel", lo que le permitiría ejercer su dominio al mundo utilizando así a los judíos como víctimas e instrumentos para lograr este objetivo. Esto está reflejado en la ubicación de todas las opciones planteadas.

\section{Argentina.}

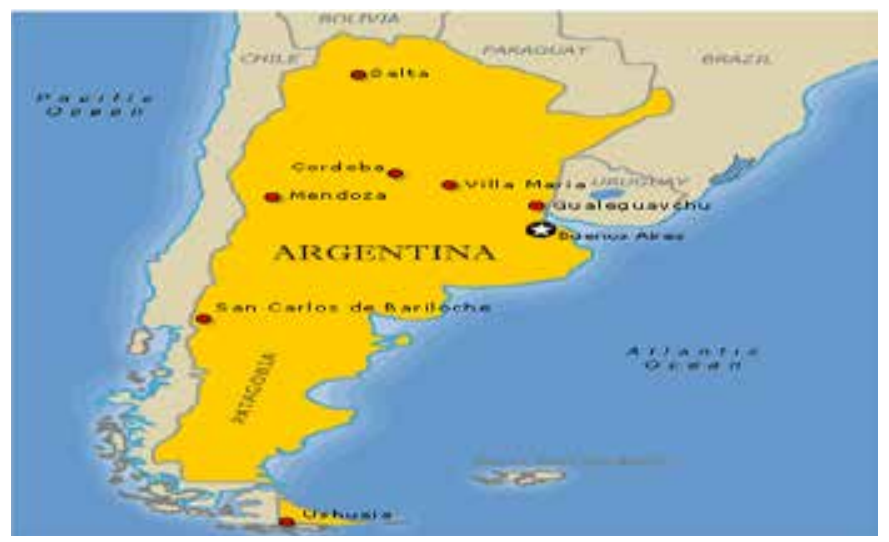

\section{Uganda y Kenia}

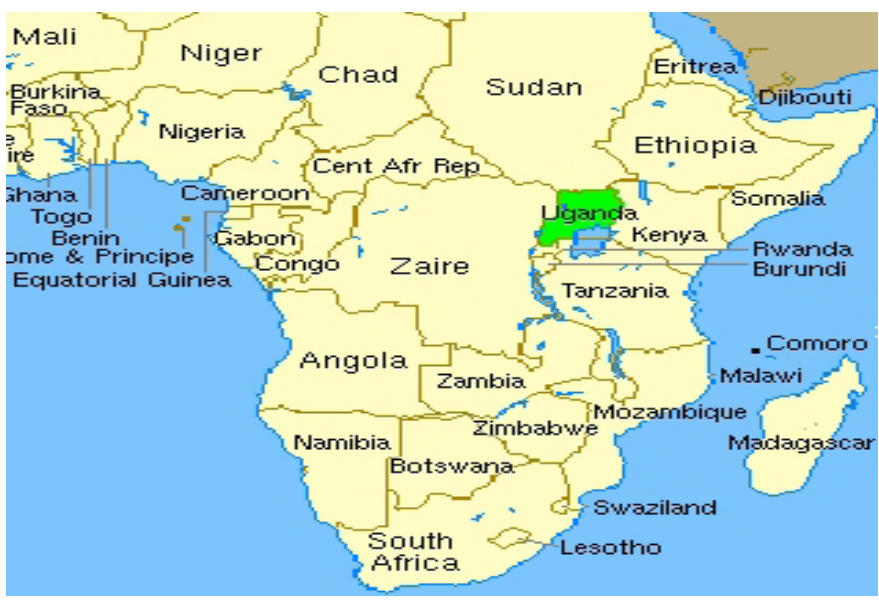

\section{Gran Israel (planteada por Israel en el Medio Oriente)}

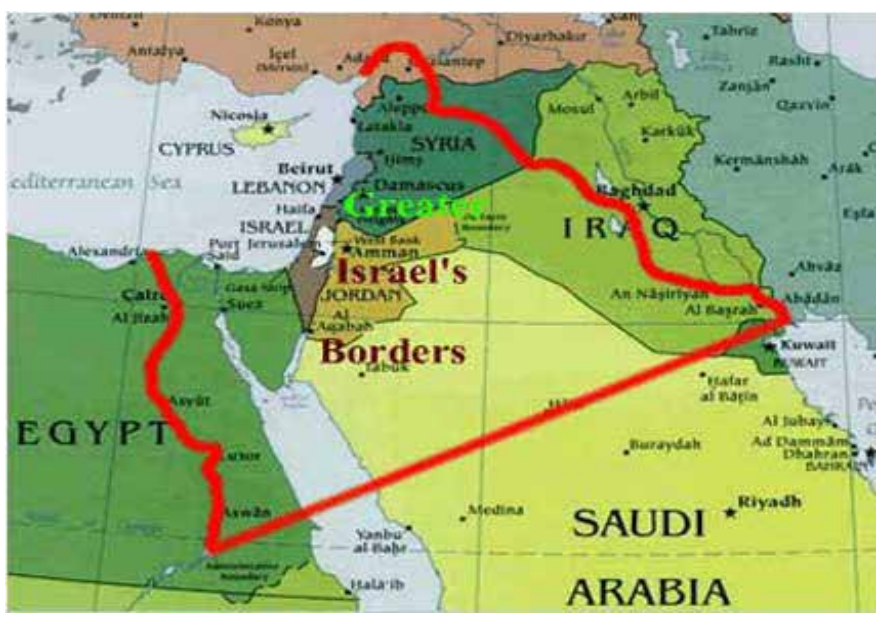

\section{Mapa del Mundo}

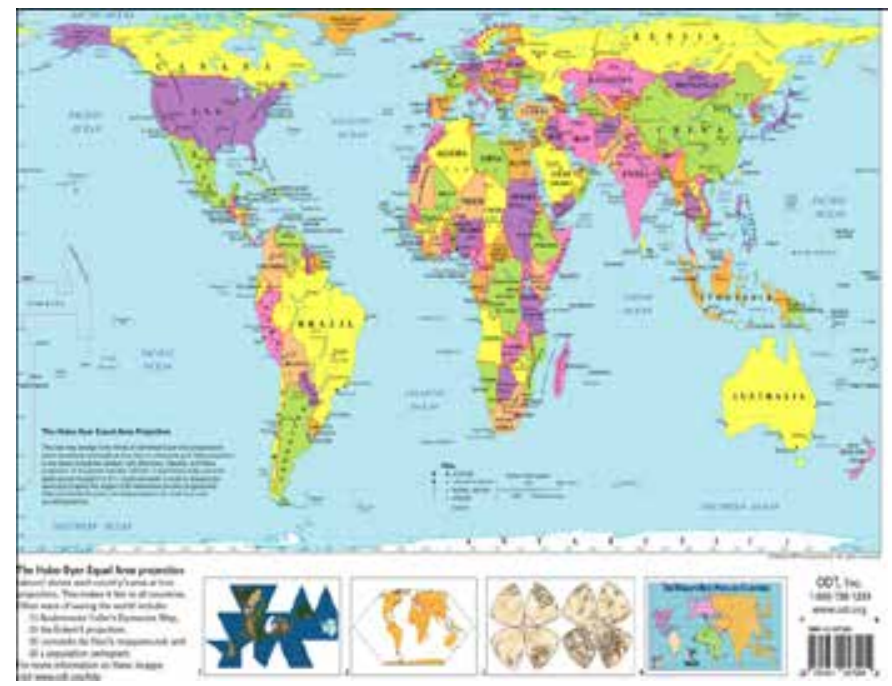

\section{DECLARACIÓN DE BALFOUR}

Después de la Primera Guerra Mundial, en Diciembre de 1917 Palestina pasó a formar parte del Dominio Británico en la zona, pero el 2 de Noviembre del año 1917 el Canciller de Inglaterra hiso una Declaración donde prometió dar un lugar a los Judíos en Palestina (Declaración de Balfour). El Mandato Británico desde el comienzo de su dominio a Palestina, facilitó que la Organización Sionista Internacional lograra su objetivo. 
Para el cumplimiento de esta promesa comenzaron a facilitar la migración Judía hacia Palestina, facilitaron armamentos a las bandas sionistas, dictaron leyes que facilitaran el dominio israelita sobre la tierra Palestina, dieron los principales cargos de gobierno a los judíos para que pudieran controlar el gobierno y la economía en Palestina. Esto se refleja con el nombramiento del Alto Comisario británico en Palestina, el Sr. Herbert Samuel, de origen Judío.

Como otro ejemplo tenemos que en agosto de 1924, el Gobierno del Mandato Británico confiscó grandes extensiones de tierra palestina, la cual fue entregada a la Agencia Judía. Al igual el Gobierno Británico donó a la empresa judía Butach un área de 75,000 hectáreas y a la compañía de electricidad judía donó un área de 18,000 hectáreas.

\section{AL NAKBA (Catástrofe)}

AlNakba se refiere a la limpieza étnica y al desplazamiento del pueblo palestino de sus tierras.

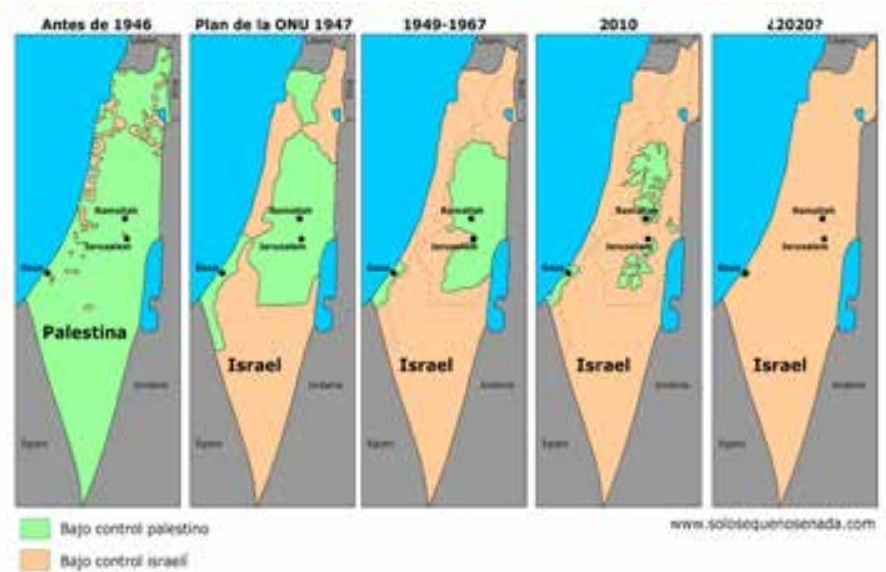

En 1946 el porcentaje de judíos en Palestina apenas llegaba al 9\%, pero debido a la migración judía hacia Palestina el porcentaje de la población judía iba aumentando.

En 1948 la población de Palestina era alrededor de 1,400,000 habitantes y los judíos alrededor de 400,000 habitantes.

El 29 de Noviembre de 1947, las Naciones Unidas en su Resolución número 181, decidió partir a Palestina en dos Estados, el PLAN DE PARTICIÓN dio a los palestinos el $43 \%$ y a los judíos el $53 \%$ de la superficie de Palestina, en particular las zonas costeras y fértiles aunque los palestinos eran la mayoría absoluta, todo esto sin consultar al pueblo palestino.

Esta injusta partición de Palestina fue aprobada por las Naciones Unidas debido a la presión que ejercieron las potencias internacionales.

El 14 de mayo de 1948, Inglaterra decidió terminar su mandato en Palestina retirándose a las 12 de la noche y en las primeras horas de la madrugada del 15 de Mayo, el Movimiento Sionista declaró la creación del Estado de Israel, algo que fue organizado por Inglaterra para darle chance al Movimiento Sionista de lograr una mayor expansión en Palestina. A raíz de esto se produjo la guerra de 1948 donde Israel logró apropiarse de más del 77\% del territorio Palestino, aplicando un proceso de limpieza étnica donde las fuerzas sionistas destruyeron más de 530 aldeas y ciudades y cometieron alrededor de 70 masacres, las que ocasionaron la muerte de más de 15,000 mártires palestinos, además del desplazamiento de casi 900,000 palestinos de sus tierras hacia Cisjordania, Franja de Gaza y los países árabes.

\section{Plan de Partición}

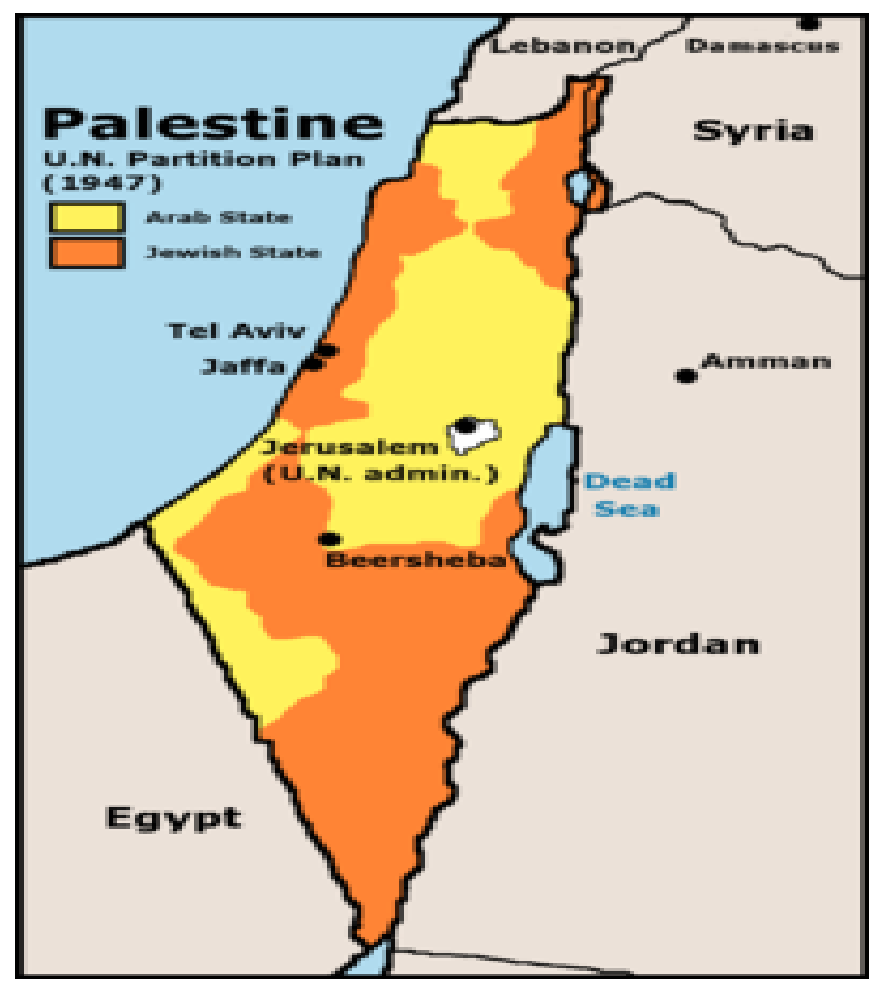




\section{GUERRA DEL 67}

El 5 de junio de 1967, Israel inició una guerra contra los países árabes donde ocupó lo que quedó de Palestina (Gaza y Cisjordania), una parte de Egipto (Sinaí), una parte de Siria (las alturas del Golán), y anexa las alturas del Golán al Estado Israelí al igual que Jerusalén Oriental, en una clara expresión de la naturaleza expansionista del Estado Sionista y una materialización de su visión del "Gran Israel", explicando así el permanente rechazo israelí de limitar sus fronteras.

Las Naciones Unidas emitió la Resolución 242, en la cual exige el retiro de las tropas israelíes de los territorios ocupados, pero Israel ha ignorado esta resolución hasta el día de hoy.

\section{REFUGIADOS}

Tanto el Nakba como la Guerra del 76, ha producido grandes cantidades de Refugiados.

Las estadísticas indican que los refugiados en el territorio palestino forman el $45 \%$ de los palestinos que viven en Palestina, esta estadística es del 2009 y el número de los refugiados registrados en UNRWA son 4.7 millones de refugiados que forman el $43.4 \%$ del total de la población palestina en el mundo.

Los refugiados palestinos viven en 58 campamentos distribuidos de la siguiente manera:

- Jordania: 10 campamentos con el $41.7 \%$ de los refugiados.

- Siria: 9 campamentos con el 9.9\% de los refugiados.

- Líbano: 12 campamentos con el 9\% de los refugiados.

- Cisjordania: 19 campamentos con el 16.3\% de los refugiados.

- Gaza: 8 campamentos con el 23.1\% de los refugiados.

- En esto no se incluye a los refugiados después de 1948.

- Estos refugiados son uno de los resultados del Nakba y de la Guerra del 67.

A pesar de la Resolución 194 tomada por las Naciones Unidas el 11 de diciembre de 1948, la cual establece el retorno de los refugiados, Israel no cumple esta resolución, además de las Resoluciones \#2672, emitida el
8 de Diciembre de 1970, \#3089, emitida el 7 de Diciembre de 1973 y la \#3236, emitida el 22 de Noviembre de 1974.

Actualmente casi la mitad del pueblo palestino, vive fuera de su tierra y gran parte de ellos en campamentos bajo condiciones difíciles, ni siquiera pueden ver a sus familiares en Palestina desde hace muchos años.

Desplazar a las personas de sus tierras es una gran violación de los derechos humanos, donde la comunidad internacional debe asumir su responsabilidad al respecto.

\section{PRISIONEROS PALESTINOS}

La causa de los prisioneros palestinos es uno de los más grandes problemas humanitarios, políticos y jurídicos en la historia moderna, en especial porque un tercio del pueblo palestino ha sido encarcelado a lo largo de los años de lucha contra la ocupación israelí. El número de palestinos encarcelados desde 1948 asciende a más de 800 mil palestinos, en una de las más grandes operaciones de arresto en la historia moderna.

Se estima que en cada casa palestina por lo menos ha sido arrestado uno de sus miembros ya sea hombre, mujer o niño. Los años de la Primera Intifada en 1987 y la Segunda Intifada en el año 2000, se estima que hubo entre 500 a 700 arrestos mensualmente.

Cabe destacar que desde 1967 hasta la fecha, han muerto más de 204 prisioneros como consecuencia de la tortura y negligencia médica a la que han sido sometidos.

Actualmente hay más de 7,000 prisioneros palestinos, entre ellos 250 niños, 16 mujeres y 32 diputados.

Israel tiene a estos prisioneros bajo condiciones muy difíciles aplicándoles distintos métodos de torturas.

Uno de los grandes problemas que enfrentan los prisioneros palestinos es el arresto por la llamada Detención Administrativa, por medio de la cual detienen a las personas sin cargos, ni juicios, ni sentencia y sin permitirle al prisionero o abogado del mismo defenderse por la inexistencia de pruebas incriminatorias, bajo el pretexto del archivo secreto donde el prisionero puede estar años en la cárcel sin ser juzgado. Hoy en día existen alrededor de 500 prisioneros encarcelados bajo este concepto, inventado por Israel. 
La política israelí clasifica a los prisioneros palestinos como terroristas para ocultar el terrorismo de Estado aplicado contra el pueblo palestino, a pesar de que son presos políticos ejerciendo su derecho de defender sus tierras, un derecho que está garantizado por las Naciones Unidas.

Esta violación de derechos humanos que aplica Israel contra los prisioneros Palestinos, necesita una fuerte intervención por parte de la comunidad internacional para mejorar sus condiciones y liberarlos

\section{ASENTAMIENTOS Y MURO DE SEGREGACIÓN RACIAL}

Los asentamientos israelíes son colonias construidas por Israel a partir de 1968 en territorios palestinos ocupados después de 1967.

El dominio de los territorios palestinos forma la esencia del movimiento sionista internacional, este dominio siempre está acompañado de cambios demográficos. Actualmente existen en Cisjordania alrededor de 500 sitios de asentamientos donde viven casi medio millón de israelitas. La mayor parte de ellos viven en Jerusalén Oriental.

El 23 de junio del 2002, el gobierno israelí decidió construir un muro con el objetivo de cambiar la realidad en el terreno y obstaculizar el Establecimiento del Estado Palestino en los territorios ocupados en 1967 y la Judaización de Jerusalén.

Es una barrera construida por el gobierno israelí que se extiende aproximadamente en un $20 \%$ a lo largo de la línea verde (Frontera del 67) y el $80 \%$ restante en territorio palestino. Israel pretende extender este muro 757 kilómetros. Actualmente terminaron de hacer la construcción de más de 444 kilómetros.

Este muro pretende dividir a Cisjordania en cantones separados, confiscando alrededor del $20 \%$ de los territorios de Cisjordania.

Según la decisión de la Haya el 9 de julio del 2004, el muro es una clara violación de las leyes humanas e internacionales.
El problema del Muro y los Asentamientos son unos de los grandes problemas que afectan al pueblo palestino debido a que es un robo de tierra, es una judaización del terreno, es la división de Cisjordania en cantones y tiene como objetivo obligar a nuestro pueblo a abandonar sus tierras, lo cual es una violación a los derechos humanos y a la ley internacional.

Las Naciones Unidas ha emitido muchas Resoluciones en relación al Muro y a los Asentamientos como las Resoluciones \#446 emitida el 22 de Marzo de 1979, \#51223, emitida el 13 de Marzo de 1997, \#10-6, emitida el 9 de Febrero de 1999, \#10-13, emitida el 12 de Octubre 2003, y la \#10-15, emitida el 21 de Julio del 2004, considerándolos como ilegales, los cuales deben ser eliminados, pero Israel continúa su robo de tierra sin cumplir con ninguna de estas Resoluciones.

Israel no acató ninguna de estas resoluciones y sigue materializando sus ideas expansionistas con el objetivo de evacuar las tierra palestina de sus dueños e impedir y obstaculizar la solución de dos Estados.

Ante estas violaciones la comunidad internacional debe asumir una fuerte posición, no solo porque es una violación de la ley internacional, sino porque también obstaculiza la realización de dos Estados como solución al conflicto.

Ante el rechazo israelita de aceptar y cumplir con las leyes internacionales hay que aplicar medidas para que prevalezca la Ley Internacional.

\section{Sitios coloniales israelitas en la Franja de Gaza.}

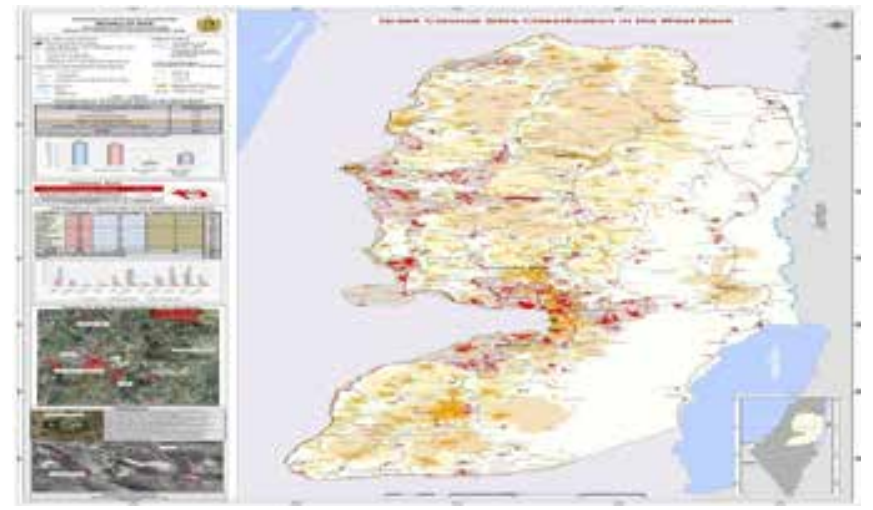




\section{INICIATIVA ÁRABE DE PAZ Y ACTITUD ISRAELITA}

Ante este conflicto, los países Árabes en el año 2002 y con el objetivo de poner fin a este conflicto plantearon una iniciativa la cual consistía en declarar el fin del Conflicto Árabe - Israelí y establecer relaciones normales entre Israel y los países árabes a cambio de la retirada israelí de los territorios ocupados en el $67 \mathrm{y}$ el establecimiento del Estado de Palestina en los territorios ocupados en el 67. Israel rechazó esta iniciativa y tampoco planteó una iniciativa para resolver el conflicto y hasta el momento no ha definido sus límites, siendo el único país que no tiene sus límites definidos.

Ante esta posición israelita nos preguntamos:

¿Qué quiere Israel? Acaso quiere seguir con su política expansionista toda la vida.

\section{Las últimas guerras contra Gaza}

\section{Primera Guerra:}

Entre el 27 de diciembre 2008 y el 17 de enero 2009, la fuerza israelí lanzó una brutal agresión contra nuestro pueblo en la Franja de Gaza donde mataron a más de 1,400 personas, entre ellos 313 niños, 116 mujeres y alrededor de 5,450 heridos, entre ellos 1,606 niños y 828 mujeres, además de las pérdidas materiales que fueron contabilizadas en casi dos mil millones de dólares en daños en infraestructura y casas.

\section{Segunda Guerra:}

En la guerra de noviembre 2012, Israel asesinó al jefe militar de Hamas y producto de esto inicio la guerra que duró una semana donde murieron 191 personas y 1,500 heridos, la mayor parte de ellos civiles además de la destrucción de infraestructura (casas, instituciones, centros de educación).

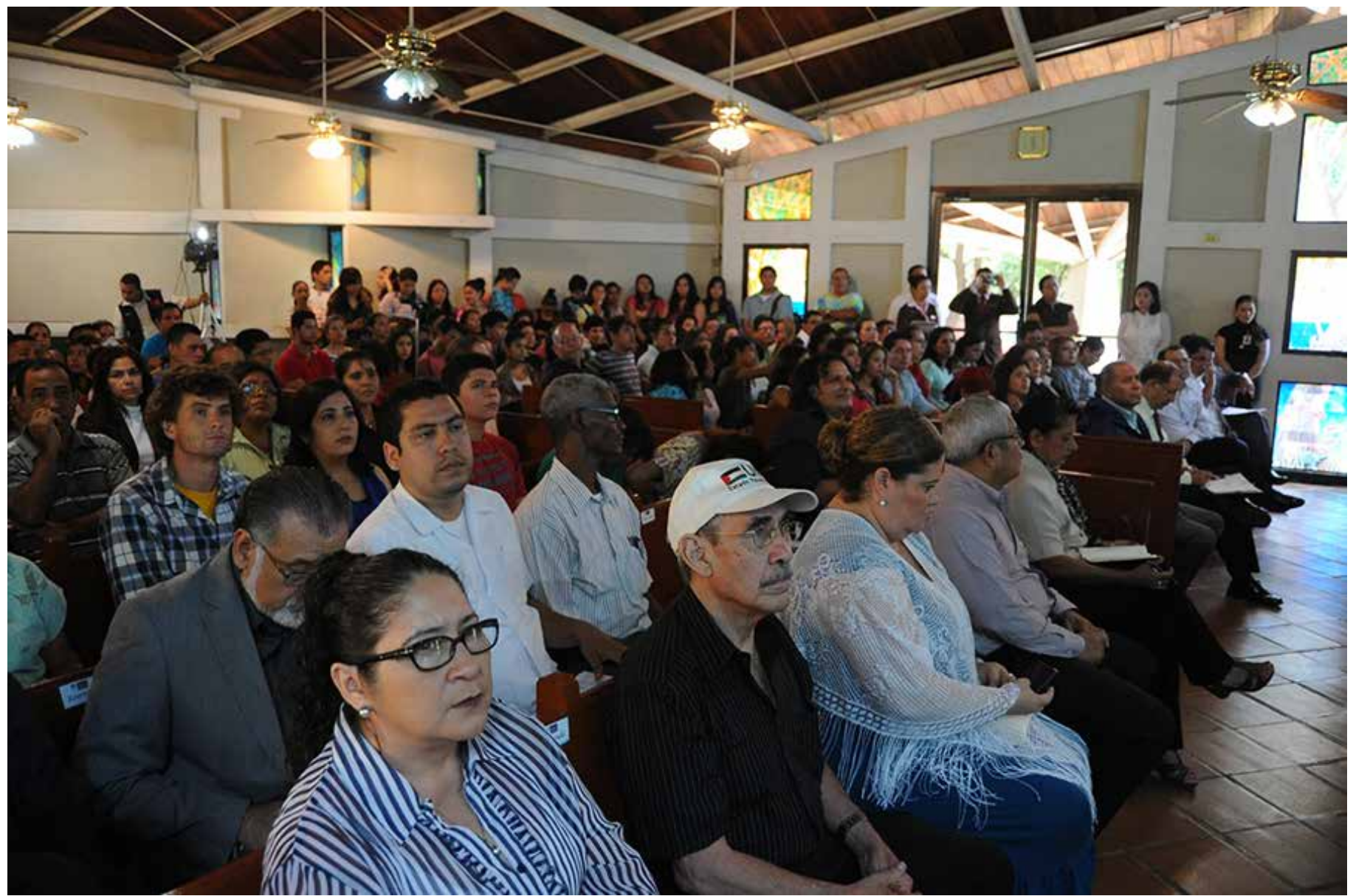

Público asistente a la Conferencia Magistral del Embajador de Palestina. Foto Relaciones Públicas UPOLI 


\section{Tercera Guerra:}

La cual se llevó a cabo del 7 de julio al 26 de agosto 2014, dejando como resultado 2,147 muertos, entre ellos (530 niños, 302 mujeres, 22 miembros de equipos médicos, 16 periodistas y 11 funcionarios de Naciones Unidas) 10,870 heridos, entre ellos 3,303 niños y 2,101 mujeres, 17,132 casas destruidas y 39,050 casas dañadas, 222 escuelas destruidas, 171 mezquitas destruidas, además del daño ocasionado a Hospitales, clínicas y ambulancias.

La pérdidas totales se estiman en 4,000 millones dólares. Se estima que la cantidad de explosivos lanzados equivalen a tres bombas atómicas.

Cuando vemos la cantidad de masacres, muertos y heridos y destrucciones podemos hablar de un verdadero Holocausto palestino.

La pregunta es ¿Hasta cuando Israel va a seguir con sus masacres contra el pueblo palestino? y ¿Cuándo la Comunidad Internacional va a tomar decisiones que protejan al pueblo palestino y garanticen sus derechos de construir su Estado independiente?

\section{CONCLUSIONES}

Según todo lo mencionado anteriormente el conflicto se caracteriza por lo siguiente:

- Política expansionista por parte de Israel.

- Rechazo a las Resoluciones internacionales por parte de Israel.

- El intento de Israel de cambiar la realidad del terreno.

- Grandes violaciones a los Derechos Humanos por parte de Israel.

- Aplicación de exterminio y limpieza étnica contra el pueblo palestino por parte de Israel.

- Tendencias fascistas por parte de Israel y esto lo dicen escritores israelitas.

- Violaciones a la Ley Internacional por parte de Israel y rechazo de iniciativas de paz.

- Preocupación de desestabilización a nivel regional e internacional (Guerras regionales y mundiales)

Esta conducta israelita no solo afecta a los palestinos sino también a los judíos que se están convirtiendo en víctimas de esta Política israelí.
Ante esta situación hay una responsabilidad internacional de resolver este conflicto, proteger y hacer valer la Ley Internacional garantizando los derechos del pueblo palestino de establecer su Estado Independiente para poder vivir en paz al igual que el resto de los pueblos del mundo y poner fin a la última ocupación que existe en el mundo, y para esto no basta la condena, hay que aplicar sanciones por la comunidad internacional.

El establecimiento del Estado palestino es una necesidad, no solo porque se trata del derecho de un pueblo sino también porque se trata de violaciones a los derechos humanos universales. Se trata de poner fin a una política expansionista y a un conflicto que data de más de 66 años de exterminio sin respeto a ley internacional, se trata de frenar tendencias fascistas, de proteger la ley internacional y el establecimiento de la paz con justicia y la convivencia internacional.

El establecimiento del estado palestino independiente es la solución que puede garantizar la paz en una de las zonas más sensibles del mundo. Este es el momento en que la comunidad internacional debe ejercer una fuerte presión para establecer la paz y la justicia mundial.

\section{ANEXOS}

\section{(Algunas resoluciones tomadas por las Naciones Unidas en relación al conflicto)}

\section{Resolución de la guerra de 1967}

El 22 nov. De 1967 Resolución 242 del Consejo de Seguridad. Se pide a Israel: 1.- La retirada de las fuerzas armadas de los territorios ocupados en la Guerra de los Seis Días de 1967 y 2.- "el reconocimiento de la soberanía, integridad territorial e independencia política de todos los estados de la región y su derecho a vivir en paz dentro de límites seguros y libres de amenazas o actos de fuerza

Resoluciones de la guerra de 1973

\section{Resolución 338}

Adoptada por el Consejo de Seguridad el 22 de octubre de 1973,

1. Insta a todas las partes en la presente lucha a que cesen el fuego y pongan fin a toda actividad militar inmediatamente, a más tardar 12 horas después del 
momento de la aprobación de esta decisión, en las posiciones que ahora ocupan.

2. Insta a las partes interesadas a que empiecen inmediatamente después de la cesación del fuego la aplicación de la Resolución 242 (1967) de 22 de noviembre de 1967 del Consejo de Seguridad en todas sus partes;

3. Decide que, inmediatamente y en forma simultánea con la cesación del fuego, se inicien negociaciones entre las partes interesadas, con los auspicios apropiados encaminados al establecimiento de una paz justa y duradera en el Oriente Próximo.

\section{Resoluciones sobre los asentamientos y el muro}

\section{9}

22 mar. Resolución 446 del Consejo de Seguridad sobre los asentamientos: Determina que "la política y las actuaciones de Israel de establecimiento de asentamientos en los territorios palestinos y árabes ocupados no tienen validez legal y constituyen un serio obstáculo para la consecución de una paz justa, global y duradera en Oriente Medio"

\section{7}

13 mar. Resolución 51/223, se exhorta a Israel a no construir asentamientos en los territorios árabes ocupados, especialmente en Jerusalén.

\section{9}

9 feb. Resolución 10/6, condena el incumplimiento por parte de Israel de las resoluciones de la ONU y pide el cese "total e inmediato" de todas las actividades relacionadas con los asentamientos judíos.

\section{3}

21 oct. Resolución $10 / 13$, pide a Israel que paralice y elimine el muro que está construyendo en territorio palestino, por ser contrario al derecho internacional.

\section{4}

21 jul. Resolución 10/15, exige a Israel cumplir el dictamen judicial que declara ilegal el muro, pero con más peso simbólico que efectivo puesto que el Estado judío se manifestó en contra y considera que nada le obliga a cumplirla.

\section{Resoluciones de la ONU sobre los refugiados palestinos}

\section{8}

11 dic. Resolución 194 . Establece que los refugiados tienen derecho a regresar a sus casas, ahora en territorio de Israel, o recibir una compensación económica en el caso de que no deseen volver.

\section{0}

8dic. Resolución $\mathrm{N}^{\circ} 2672$, en los párrafos a, b, c, d, se llama a Israel a trabajar inmediatamente en el retorno de los refugiados, la organización reconoce al pueblo Palestino igualdad de derechos y el derecho a la libre determinación, de conformidad con la Carta de las Naciones Unidas.

\section{3}

7dic. Resolución $\mathrm{N}^{\circ}$ 3089, llama al pleno respeto de los derechos no inalienables del pueblo palestino, especialmente su derecho a la libre determinación, para lograr una paz justa y duradera en el Oriente Medio, y que los refugiados árabes palestinos tienen el derecho al retorno.

\section{4}

22 nov. Resolución $\mathrm{N}^{\circ} 3236$, reafirma los derechos no inalienables del pueblo palestino, especialmente el derecho a la libre determinación sin injerencia externa, el derecho a la independencia y la soberanía nacional, y el regreso de los refugiados a sus hogares y propiedades de los que fueron desplazados y desarraigados. 